\title{
The relationship between isokinetic knee strength and jumping in young male volleyball players
}

\author{
${ }^{1}$ Hacettepe University, Department of Exercise and Sport Sciences, Ankara, Turkey \\ ${ }^{2}$ Gazi University, Department of Trainer Education, Ankara, Turkey \\ ${ }^{3}$ Turkish Volleyball Federation, Head Coach of Male Volleyball Team, Ankara, Turkey \\ ${ }^{4}$ Gazi University, Institute of Health Sciences, Ankara, Turkey \\ Address correspondence to E. Öz, e-mail: elifoz@gazi.edu.tr
}

Barbaros ÇELENK¹, Elif ÖZ², Akif Gökhan ÖNER ${ }^{3}$, Elvan ÖZ4

\begin{abstract}
Volleyball is a dynamic physical game that does not have a definite match duration but is based on high tempo, quickness, strength, flexibility, endurance and jumping. The aim of this study is to research the relationship between isokinetic knee strength and jumping height in young male volleyball players. 8 male volleyball players aged between 18-22 participated in the research voluntarily. In the study, the physical characteristics of the subjects (body height, body weight, body mass index) were determined, vertical jump heights were measured and at low $\left(60^{\circ} \cdot \mathrm{s}^{-1}\right)$ and high $\left(300^{\circ} \cdot \mathrm{s}^{-1}\right)$ speeds, the right and left knee flexion/extension concentric isokinetic strength test was applied. Data was analyzed with paired sample t-test and Pearson correlation coefficient test was used to determine the relationship between vertical jump and isokinetic strength $(p<0.05)$. The right and left knees peak torque of the athletes were compared at low and high angular speeds and no significant difference was found. A significant positive correlation was detected between the jumping height and the right knee peak torque at low angular speed $(\mathrm{r}=.817, \mathrm{p}<0.05)$. This result can be explained by the fact that quadriceps femoris, which is the biggest muscle of the lower extremity, is in the foreground during the jumps that volleyball players perform frequently. It may be advisable to give importance to leg strength training to increase the jump height.
\end{abstract}

Keywords: volleyball, vertical jump, isokinetic strength, peak torque

\section{INTRODUCTION}

The fact that the elite volleyball players jump 100-150 times during a match reveals the need for volleyball players' leg strength for jumping (14). In another study conducted on elite men volleyball players, 250 - 300 high-power activity was reported in which athletes jumped in various ways $(50 \%$ of them require the hip extension, knee extension and ankle plantar flexion) (8).

Explosive strength and jump strength of the leg muscles in volleyball players are undoubtedly important neuromuscular performance characteristics (10). In volleyball, quadriceps and hamstrings muscle groups participate in important motor skills such as jump (13). When the jump movement is considered, it is found that flexor and extensors are effective in these muscle groups. The most powerful group of knee extensors is the quadriceps muscle group that performs the most powerful extension movement. Due to the need for greater power in terms of duty, they are 2.5 times larger in volume than hamstrings (10). 
Volleyball nowadays is one of the most explosive and fast sports branches including much improved muscle strength, power, agility and speed $(2,5,6,7)$. In addition to the technique, it is known that the muscular strength is important in increasing the vertical jump used in the spikes and isokinetic exercises are the most effective method of gaining strength and isokinetic dynamometers where these exercises can be performed.

Vertical bounce is frequently encountered in volleyball in spike, block and service techniques (When the setters set up a game by jumping, they perform vertical jump). Sattler et al. (16) found that the isokinetic strength data was more closely related to block jump than the spike jump in female volleyball players. However, they reported that the eccentric isometric measurements were an important determinant for spike jump.

We assume that there may be a relationship between the vertical jump, in which the most powerful extensor quadriceps femoris muscle played an agonist role, and the isokinetic strength produced at the knee joint extension at different angular velocities. Therefore, the aim of this study is to research the relationship between isokinetic leg strength and jumping height in young male volleyball players.

\section{MATERIAL \& METHOD}

8 (healthy) male volleyball players aged between 18-22 participated in the study voluntarily. Each participant was informed about the content of the study and their consent was obtained.

The body height and body weight were measured after taking the position in anatomical posture in such a way that heels adjacent, holding breath, head on the frontal plane, overhead plate touching the vertex point and the measurements were recorded in "cm" and "kg". The body height of the subjects was measured with stadiometer with a precision of $\pm 1 \mathrm{~mm}$ (Seca 213). The body weights were measured with an electronic scale with a precision of \pm $100 \mathrm{~g}$ (Seca 760).

Vertical jumps of the subjects were measured by the Vertical Jump meter T.K.K. 5106 Jump-MD. The athletes started the test in half squat position that the knees would not cross the toes and the hands were in the waist. Attention was paid that the athletes' falling positions and body postures were equal.

Turk ل Sport Exe 2019; 21(1): 12-15

๑ 2019 Faculty of Sport Sciences, Selcuk University
The isokinetic strength test was performed with CSMI-Cybex Humac Norm Isokinetic Test and Exercise System. Subjects were subjected to isokinetic strength measurement after $10 \mathrm{~min}$ general and $5 \mathrm{~min}$ special warming. The range of motion belonging to that joint was found by the computer by having the subject make a movement. After the test measurements were taken, the test values specified according to the protocol were transferred to the computer. Isokinetic tests were applied concentric for right and left knees as 5 repeats at $60^{\circ} . \mathrm{s}^{-1}$ angular speed and 15 repeats at $300^{\circ} \cdot \mathrm{s}^{-1}$ angular speed by eliminating the effect of gravity. In the measurements made in these joint movements, the gravity effect, which may cause incorrect results, is also reset by the device.

Physical characteristics of athletes, descriptive statistics on data obtained from vertical jump and isokinetic strength measurements were calculated. The normality test was applied to the data analysis and data showed normal distribution. Paired sample t-test was used in the analysis of measurements and Pearson correlation test was used to determine the relationship between vertical jump and isokinetic strength. SPSS 22.0 package program was used for statistical analysis of the data. The significance level was taken as $\mathrm{p}<0.05$.

\section{RESULTS}

Physical characteristics of subjects, jump data and peak torque at different angular speeds are presented in Table 1.

\begin{tabular}{|c|c|c|c|c|}
\hline & Minimum & Maximum & Mean & SD \\
\hline Age (years) & 18 & 22 & 20.5 & 1.69 \\
\hline $\begin{array}{l}\text { Body height } \\
(\mathrm{cm})\end{array}$ & 187 & 202 & 196 & 5.33 \\
\hline $\begin{array}{l}\text { Body weight } \\
(\mathrm{kg})\end{array}$ & 82 & 98 & 90.4 & 6.30 \\
\hline $\begin{array}{l}\text { Body mass } \\
\text { index }\left(\mathrm{kg} / \mathrm{m}^{2}\right)\end{array}$ & 22.3 & 25 & 23.5 & 0.78 \\
\hline $\begin{array}{l}\text { Vertical jump } \\
\text { height }(\mathrm{cm})\end{array}$ & 62 & 94 & 79.1 & 9.42 \\
\hline
\end{tabular}

Right \& left knee peak torque of the athletes at low and high angular velocities were compared and no significant difference was found (Table 2). 
Table 2. Comparison of quadriceps femoris peak torque at low and high angular velocities of subjects

\begin{tabular}{lccc}
\hline Peak torque $(\mathrm{Nm})$ & Mean & SD & $\mathrm{p}$ \\
\hline Right knee $60^{\circ} \cdot \mathrm{s}^{-1}$ & 340 & 42.1 & \\
Left knee $60^{\circ} \cdot \mathrm{s}^{-1}$ & 327 & 47.3 & 0.455 \\
\hline Right knee $300^{\circ} \cdot \mathrm{s}^{-1}$ & 177 & 23.7 & \\
Left knee $300^{\circ} . \mathrm{s}^{-1}$ & 166 & 19.5 & 0.245 \\
\hline
\end{tabular}

A significant positive correlation was determined between the jump height and the right knee peak torque at low angular speed $(\mathrm{r}=.817$, $\mathrm{p}<0.05$ ) (Table 3).

Table 3. The relationship between vertical jump and isokinetic strength of subjects.

\begin{tabular}{lcc}
\hline & \multicolumn{2}{c}{ Vertical jump $(\mathrm{cm})$} \\
\cline { 2 - 3 } & $\mathrm{r}$ & $\mathrm{p}$ \\
\hline Right knee $60^{\circ} . \mathrm{s}^{-1}$ peak torque $(\mathrm{Nm})$ & .817 & .013 \\
Right knee $300^{\circ} . \mathrm{s}^{-1}$ peak torque $(\mathrm{Nm})$ & .313 & .450 \\
Left knee $60^{\circ} . \mathrm{s}^{-1}$ peak torque $(\mathrm{Nm})$ & .629 & .095 \\
Left knee $300^{\circ} \cdot \mathrm{s}^{-1}$ peak torque $(\mathrm{Nm})$ & .669 & .069 \\
\hline
\end{tabular}

\section{DISCUSSION and CONCLUSION}

In this study, the relationship between jumping performance and isokinetic knee strength of the male volleyball players was studied and a meaningful positive relationship was found between the jump height and right knee peak torque in low angular velocity $(\mathrm{r}=.817, \mathrm{p}<0.05)$.

The performance of a volleyball player is directly affected by the power generation capacity. The strongest players reach a good strength level in a short time (17). One of the most important characteristics of volleyball is the need for athletes to reach the highest jump height in movements such as attacks and block. For this, high power generation is required, especially in the lower extremity (16).

Isokinetic dynamometer tests, include strength, torque and power measurements through the performance of constant-speed joint movements (3). The speeds used in isokinetic dynamometer evaluations allows measurement of strength at different angular speeds from lower angular speeds allowing larger torque production (30 ve $60^{\circ} . \mathrm{s}^{-1}$ ), to higher angular speeds such as $300^{\circ} . \mathrm{s}^{-1}$ which is closer to the contraction rate of the knee joint muscles used in sports applications (4). Considering that the jumps are multiple joint movements with the contribution of $49 \%$ knees, $28 \%$ hip and $23 \%$ ankles, (9), tests performed on an isokinetic dynamometer may be associated with the jump performance of the volleyball players (including knee flexion and extension) (17).

Bosco et al. (1) used squat jump, counter movement jump and depth jump tests to measure vertical jump height. In these three jumps, the highest correlation between the strength of the knee extensor applied in the isokinetic dynamometer occurs through counter movement jump $(\mathrm{r}=0.74)$, followed by a squat jump $(r=0.71)$ and depth jump $(r=0.60)$. In other studies, the authors found a positive correlation between knee strength and jumping performance at low speed $\left(60^{\circ} . \mathrm{s}^{-1}\right)$. ((12), $\left.\mathrm{r}=0.40 ;(17), \mathrm{r}=0.82\right)$.

In the study, where Sattler et al. (16) examined the relationship between volleyball players' block \& spike jump heights and isokinetic strength, determined that the data of the subjects (women \& men) had a higher correlation coefficient with block jump $\left(r^{2}=0.39\right.$ and $r^{2}=0.36$, respectively) compared to the spike jump $\left(r^{2}=0.42\right.$ and $r^{2}=0.37$, respectively).

In the study conducted by Laudner et al. (11), while there was a low correlation found between peak torque of knee flexors and jump height $(\mathrm{r}=0.39$ to $r=0.58$ ), a high correlation was found between peak torque of knee extensors and jump height $(r=0.63$ to $r$ $=0.74)$. This result shows that knee extensors are more important than knee flexors in jumping.

Yapici et al. (18), at the speed of $60^{\circ} . \mathrm{s}^{-1}$, there was a higher correlation found between concentric pe ak torque and squat jump, counter movement jump (squat jump - $\mathrm{r}=0.80$ and counter movement jump - $\mathrm{r}$ $=0.82$ ) compared to eccentric peak torque of knee extensors (squat jump - $\mathrm{r}=0.50$ and counter movement jump - $r=0.48$ ). These data are consistent with the correlation we found between the knee extensor concentric contractile strength and the vertical jump at low angular velocity $\left(60^{\circ} . \mathrm{s}^{-1}\right)(\mathrm{r}=.817)$.

In another study in which the isokinetic evaluation was associated with sporting skill, Saliba and Hrysomallis (15) examined the relationship between isokinetic strength and shot performance, vertical jump in Australian football players. In their study, they applied knee flexion/extension at angular velocities of $60-240-360^{\circ} . \mathrm{s}^{-1}$. There was no significant relationship found between isokinetic strength and maximal shot velocity, but they found a significant relationship between muscle strength and vertical 
jump in isokinetic measurements $(\mathrm{r}=0.55-0.69, \mathrm{p}<$ 0.05).

Consequently, at the low and high angular velocities, the right and left knee (dominant vs. nondominant) peak torque values of the athletes were compared and no significant difference was found. In addition, a significant positive relationship was found between the right knee peak torque value at low angular velocity with jump height. Due to the need to

\section{REFERENCES}

1. Bosco C, Mognoni P, Luhtanen P. Relationship between isokinetic performance and ballistic movement. European Journal of Applied Physiology and Occupational Physiology, 1983; 51(3): 357-364.

2. Cisar CS, Corbelli J. The volleyball spike: A kinesiological and physiological analysis with recommendations for skill development and conditioning programs. Strength Conditioning Journal, 1989; 11(1): 4-9.

3. Cronin JB, Hansen KT. Strength and power predictors of sports speed. The Journal of Strength and Conditioning Research, 2005; 19(2): 349-357.

4. D'Alessandro RL, Silveira EAP, Anjos MTS dos, Silva AA da, Fonseca ST da. Analysis on the association between isokinetic dynamometry of the knee's articulation and one-leg horizontal jump, hop test, in volleyball athletes. Revista Brasileira de Medicina do Esporte, 2005; 11(5): 271-275.

5. GBJ Marqeues MC, Cunha P, Resende L, Santos M, Domingos P. Changes in strength parameters during twelve competitive weeks in top volleyball athletes. International Journal of Volleyball Research, 2004; 7, 23-28.

6. Hadzic V, Sattler T, Markovic G, Veselko M, Dervisevic E. The isokinetic strength profile of quadriceps and hamstrings in elite volleyball players. Isokinetics and Exercise Science, 2010; 18(1): 31-37.

7. Harman EA, Rosenstein MT, Frykman PN, Rosenstein RM. The effects of arms and countermovement on vertical jumping. Medicine \& Science in Sports \& Exercise, 1990; 22(6): 825-833.

8. Hasegawa H, Dziados J, Newton RU, Fry AC, Kraemer WJ, Hakkinen K. Periodized Training Programmes for Athletes. In: Strength Training for Sport, Kraemer WJ and Hakkinen K, eds. Oxford, Blackwell Science, 2000.

9. Hubley CL, Wells RP. A work-energy approach to determine individual joint contributions to vertical jump performance. European Journal of Applied Physiology and Occupational Physiology, 1983; 50(2): 247-254.

10. Kalaycı A. Voleybol sakatlıkları - I. Voleybol Bilim ve Teknoloji Dergisi, 1996; 3(8), 33-38.

11. Laudner K, Evans D, Wong R, Allen A, Kirsch T, Long B, Meister K. Relationship between isokinetic knee strength and jump characteristics following anterior cruciate ligament reconstruction. International Journal of Sports Physical Therapy, 2015; 10(3): 272-280.

12. Li RC, Maffulli N, Hsu YC, Chan KM. Isokinetic strength of the quadriceps and hamstrings and functional ability of anterior cruciate deficient knees in recreational athletes. British Journal of Sports Medicine, 1996; 30(2): 161-164. produce a larger torque at low angular speed; it is advisable to give importance to leg strength training in order to increase the jump height of athletes.

\section{ACKNOWLEDGEMENTS}

This study was presented as oral presentation at the International Congress of Sports for All and Wellness in 2018.

13. Magalhaes J, Oliveira J, Ascensao A, Soares J. Concentric quadriceps and hamstrings isokinetic strength in volleyball and soccer players. The Journal of Sports Medicine and Physical Fitness, 2004; 44(2): 119-25.

14. Renstrom P. Clinical Practice of Sports Injury Prevention and Care. Blackwell Science, Oxford, 1994.

15. Saliba L, Hrysomallis C. Isokinetic strength related to jumping but not kicking performance of Australian footballers. Journal of Science and Medicine in Sport, 2001; 4(3): 336-347.

16. Sattler T, Sekulic D, Esco MR, Mahmutovic I, Hadzic V. Analysis of the association between isokinetic knee strength with offensive and defensive jumping capacity in high-level female volleyball athletes. Journal of Science and Medicine in Sport, 2015; 18(5): 613-618.

17. Schons P, Fischer G, Rosa RG, Berriel GP, Tartaruga LAP. Correlations between the strength of knee extensor and flexor muscles and jump performance in volleyball players: A review. Journal of Physical Education, 2018; 29(1): 1-12.

18. Yapici A, Findikoglu G, Dundar U. Does isokonetic angular velocity and contraction types effect predictors of different anaerobic power tests? The Journal of Sports Medicine and Physical Fitness, 2014; 56(4): 383-391. 